\title{
Полупроводниковые плазменные антенны, формируемые лазерным излучением
}

\author{
() Н.Н. Богачев ${ }^{1-3}$, Н.Г. Гусейн-заде ${ }^{1,3}$, И.В. Жлуктова ${ }^{1}$, С.Ю. Казанцев ${ }^{1, \uparrow, ~ В . А . ~ К а м ы н и н ~}{ }^{1}$, С.В. Подлесных ${ }^{1}$, \\ В.Е. Рогалин ${ }^{4}$, А.И. Трикшев ${ }^{1}$, С.А. Филатова ${ }^{1}$, В.Б. Цветков ${ }^{1,5}$, Д.В. Шохрин ${ }^{2}$ \\ ${ }^{1}$ Институт общей фризики им. А.М. Прохорова РАН, Москва, Россия \\ ${ }^{2}$ МИРЭА - Российский технологический университет, Москва, Россия \\ ${ }^{3}$ Российский национальный исследовательский медицинский университет им. Н.И. Пирогова, Москва, Россия \\ ${ }^{4}$ Институт электрофиизики и электроэнергетики РАН, Санкт-Петербург, Россия \\ ${ }^{5}$ Национальный исследовательский ядерный университет „МИФИ“, Москва, Россия \\ 9 E-mail: s-kazantsev@mail.ru
}

Поступило в Редакцию 15 августа 2019г.

В окончательной редакции 15 августа 2019г.

Принято к публикации 9 сентября 2019 г.

\begin{abstract}
Экспериментально исследована эффективность передачи высокочастотных сигналов полупроводниковой передающей антенной из монокристаллов $\mathrm{Ge}$ и $\mathrm{Si}$, на поверхности которой неравновесная электроннодырочная плазма формируется излучением лазерного диода. Получены зависимости амплитуды излучаемого СВЧ-сигнала в диапазоне $6-7.5 \mathrm{GHz}$ от мощности лазера и размера облучаемого участка на полупроводниковой передающей вибраторной антенне. Показано, что эффективность передачи полезного сигнала при формировании плазменной антенны в кристаллах Ge может быть увеличена более чем на порядок.
\end{abstract}

Ключевые слова: плазменная антенна, электронно-дырочная плазма, полупроводник, кремний, германий, лазерное излучение, СВЧ-излучение.

DOI: 10.21883/PJTF.2019.24.48793.18015n

В последнее время интенсивно изучаются возможности применения плазменных антенн в различных радиои телекоммуникационных устройствах $[1,2]$. Основные преимущества и достоинства таких антенн были рассмотрены в работах $[3,4]$. Обычно в качестве альтернативы волноведущим элементам антенн используется газоразрядная плазма, в частности получаемая при пробое газовых промежутков в условиях пониженного давления [5-8]. В настоящей работе для этой задачи рассмотрена неравновесная электронно-дырочная плазма, создаваемая при воздействии лазерного импульса на полупроводник. Оказалось, что это более удобный инструмент для управления электромагнитными свойствами объектов, чем газоразрядная плазма. Это обусловлено несколькими причинами: меньшие энергозатраты на образование свободных носителей заряда $(\sim 1 \mathrm{eV}$ в полупроводнике и $\sim 30 \mathrm{eV}$ в газоразрядной плазме); возможность получения плазмы со значительно более высокой концентрацией носителей заряда $\left(10^{16} \mathrm{~cm}^{-3}\right.$ и выше [9]); отсутствие вакуумированных компонентов; компактность и удобство использования.

В работе экспериментально показана возможность использования в качестве вибраторной антенны электронно-дырочной плазмы, возникающей на поверхности полупроводника при воздействии лазерным излучением за счет внутреннего фотоэффекта. Эксперименты выполнялись на установке, показанной на рис. 1. Излучение от лазерного источника 1 проходит через коллиматор и с помощью цилиндрической линзы 2 фокусируется на тонкую пластину из полупроводника (антенну). В результате на поверхности полупроводника формируется прямоугольное пятно шириной $1 \mathrm{~mm}$ и длиной $18 \mathrm{~mm}$. Полупроводниковая пластина 4 посредством омического контакта 5 припаивалась к разъему коаксиального кабеля, на который подавался модулированный с частотой $v=1 \mathrm{kHz}$ сигнал с СВЧ-генератора Г4-82 (6). Модуляция осуществлялась с помощью генератора прямоугольных импульсов 7. В процессе экспериментов несущая частота генератора 6 варьировалась в диапазоне 6-7.5 GHz с целью получения максимального сигнала на приемном устройстве 8 , в качестве которого использовался детекторный приемник на базе диода ДК-В7М. Меняя диафрагму 3 и перемещая лазерный источник 1 , можно варьировать как размеры облучаемой зоны на полупроводнике 4, так и ее положение относительно омического контакта. В качестве материала для пластин 4 использовались монокристаллы $\mathrm{Ge}$ с различным удельным сопротивлением и типом проводимости, а также монокристаллы высокочистого $\mathrm{Si}$. Эксперименты выполнялись с использованием в качестве непрерывного источника излучения 1 лазерного диода K976FA2RN-20.00W фирмы BWT Beijing с волоконным выводом излучения $(\lambda=975 \mathrm{~nm})$. Методика экспериментов заключалась в сравнении зарегистрированного приемником сигнала, переданного с помощью полупроводниковой антенны, и сигнала, переданного созданной с помощью оптически инициированной в полупроводнике электронно-дырочной плазмы (плазменной антенны). Для этого сначала (при 


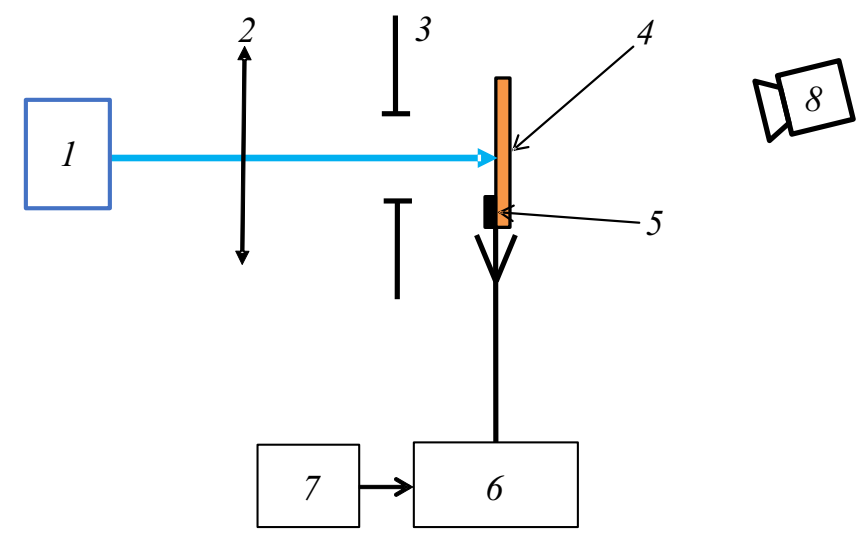

Рис. 1. Схема экспериментальной установки. 1 - лазер с длиной волны излучения $\lambda=0.9-1.1 \mu \mathrm{m} ; 2-$ цилиндрическая линза, с помощью которой на полупроводнике формируется полоска длиной $L=18 \mathrm{~mm} ; 3-$ подвижная диафрагма, за счет которой можно управлять размером области, облучаемой лазером; 4 - тонкая пластина из полупроводника; 5 - омический контакт на полупроводниковой пластине; 6 - СВЧ-генератор несущей частоты (Г4-82); 7 - задающий генератор; 8 - детекторный приемник на базе диода ДК-В7М.

выключенном лазере) на вибраторную полупроводниковую антенну с СВЧ-генератора подавался сигнал максимальной мощности, а расстояние до детекторного приемника выдерживалось максимальным, при котором еще сохранялась возможность уверенного (устойчивого) приема сигнала с генератора. После этого при данном зафиксированном расстоянии до детекторного приемника оптимизировалась передающая частота, т.е. частота СВЧ-генератора подстраивалась таким образом, чтобы получить максимальную амплитуду сигнала на приемнике. При лазерном воздействии на поверхности полупроводника образуется неравновесная электроннодырочная плазма, которая приводит к росту передаточных характеристик полупроводниковой антенны. В дальнейшем проводился сравнительный анализ сигналов на детекторе, полученных при облучении полупроводника лазерным излучением и без облучения. Установлено, что облучение как $\mathrm{Si}$-антенны, так и Ge-антенны лазерным диодом с длиной волны $\lambda=975 \mathrm{~nm}$ увеличивает их поверхностную проводимость, что повышает эффективность антенны и соответственно сказывается на увеличении регистрируемого сигнала на приемном детекторе. Наибольший рост амплитуды принимаемого сигнала с увеличением интенсивности лазерного облучения наблюдался на антеннах из Ge. Эксперименты проводились как для необлученной полупроводниковой антенны, так и при облучении ее лазерным диодом вблизи омического контакта. Область засветки - прямоугольная зона размером $1 \times 18 \mathrm{~mm}$ - начиналась непосредственно на омическом контакте, как показано на рис. 1. На рис. 2 приведены типичные осциллограммы сигналов, зарегистрированные на приемном детекторе, в случае, когда в качестве антенны выступала прямоугольная пластина размером $5 \times 45 \mathrm{~mm}$ и толщиной $1 \mathrm{~mm}$ из монокристалла Ge марки ГМО (удельное сопротивление $47 \Omega \cdot \mathrm{cm})$. Видно, что электронно-дырочная плазма, возникающая в области засветки пластины $\mathrm{Ge}$, проявляла себя как вибраторная плазменная антенна. При этом эффективность передачи сигнала существенно возрастает. Увеличение мощности лазерного излучения, воздействующего на полупроводник, приводит к росту эффективности антенны. Из рис. 3 видно, что при освещении Ge лазерным излучением $P_{l a s}=3.5 \mathrm{~W}$ амплитуда сигнала на детекторе $\left(A_{l a s}\right)$ возрастает в 10 раз по сравнению с амплитудой исходного сигнала $\left(A_{0}\right)$. Уменьшение размеров пятна облучения приводит к уменьшению длины плазменной части антенны; таким образом, вся антенна формируется из частей с различной проводимостью. Это реализуется как посредством смещения пятна облучения от омического контакта, так и путем уменьшения размеров облученной зоны с помощью диафрагмы. В этом случае происходит незначительное снижение эффективности плазменной антенны.

При использовании примесных полупроводников, уже являющихся из-за более высокой проводимости достаточно хорошими антеннами, облучение кристалла фактически лишь снижает активные потери в передатчике за счет увеличения проводимости антенны. При использовании антенн на основе, например, $p$-Ge с удельным сопротивлением $\leqslant 5 \Omega \cdot$ ст величина относительного изменения амплитуды сигнала зависела только от общей проводимости, т.е. от количества лазерной энергии,

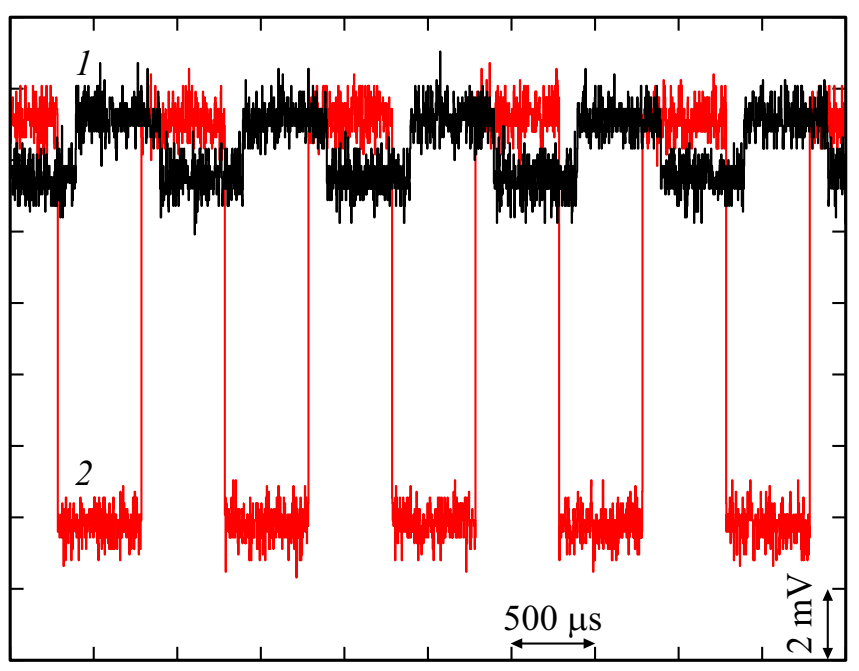

Рис. 2. Осциллограммы СВЧ-сигнала, полученные на детекторном приемнике. 1 - лазер выключен; 2 - лазер засвечивает пластину из монокристалла германия; лазерная мощность, падающая на $\mathrm{Ge}$, составляет $P_{\text {las }}=2.64 \mathrm{~W}$. Масштаб по вертикали: $2 \mathrm{mV} / \mathrm{div}$; развертка по времени: $500 \mu \mathrm{s} / \mathrm{div}$. 


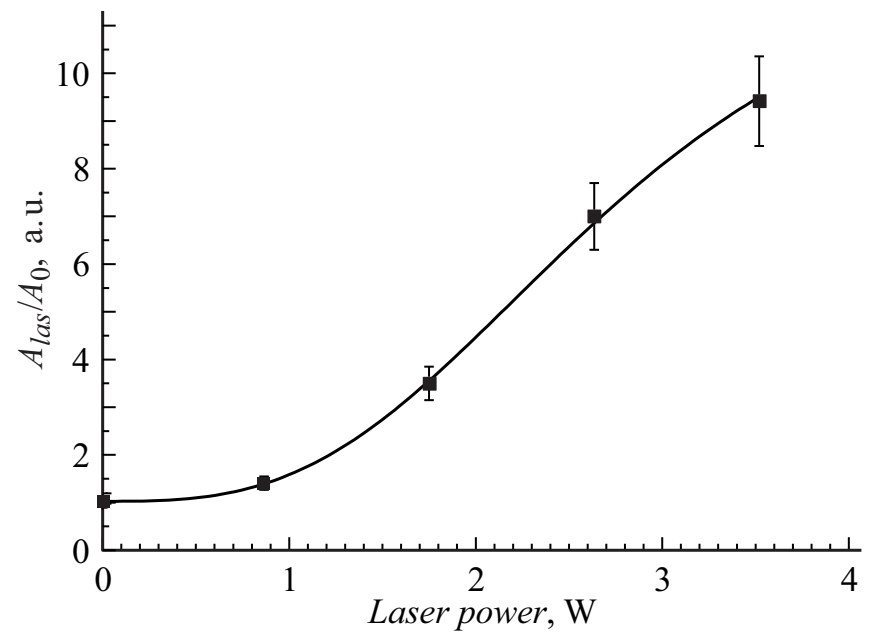

Рис. 3. Относительное увеличение амплитуды сигнала, регистрируемого детекторным приемником при облучении антенны из монокристаллического германия лазером с $\lambda=975 \mathrm{~nm}$.

поглощенной в кристалле, а не от геометрии облучения. В случае использования $\mathrm{Ge}$ в качестве материала для плазменных антенн обнаружилось, что значительное влияние на генерацию свободных носителей оказывает длительность экспозиции. В экспериментах при облучении антенны сразу после открытия диафрагмы (рис. 1) наблюдалось резкое изменение амплитуды сигнала на детекторе, затем в течение нескольких секунд происходило дальнейшее увеличение амплитуды принимаемого сигнала, которое в зависимости от падающей на кристалл лазерной мощности могло достигать 20-30\%. Для данного эксперимента с помощью численной модели $[9,10]$ были проведены оценки концентрации свободных носителей, возникающих при облучении $\mathrm{Ge}$ лазерным излучением: $n_{e} \approx 10^{15}-10^{17} \mathrm{~cm}^{-3}$. Эти оценки хорошо согласуются с данными по прямому измерению проводимости облучаемых образцов кристалла Ge.

Таким образом, в работе предложен метод создания полупроводниковой плазменной антенны с помощью лазерного излучения. Метод обладает большими перспективами для создания управляемых антенн. Описана первая успешная реализация полупроводниковой плазменной дипольной антенны для передачи излучения СВЧ-диапазона. Экспериментально доказана возможность управления эффективностью передачи сигналов СВЧ-диапазона за счет регулирования интенсивности засветки полупроводниковой вибраторной антенны лазерным излучением.

В настоящее время ведутся интенсивные исследования по созданию приемопередающих устройств терагерцевого $(\mathrm{THz})$ диапазона $\left(\sim 3 \mathrm{~mm}-30 \mu \mathrm{m} ; 3-300 \mathrm{~cm}^{-1}\right)$, пограничного между оптическим и радиодиапазоном [11]. В этом диапазоне более перспективными для использования в качестве плазменных антенн на основе полупроводников, облучаемых лазером (или светом высокой интенсивности), могут быть отражательные антенные решетки [4,12], а также перспективно управление коэффициентом преломления и отражения падающего излучения в спектральной области $\lambda=0.1-0.01 \mathrm{~cm}$. Известно, что $\mathrm{Ge}$ и $\mathrm{Si}$ широко используются в устройствах, работающих в ТНz-области спектра [13], поэтому, формируя с помощью лазера плазму нужной концентрации в полупроводниковых структурах, можно создавать управляемые поглотители THz-диапазона [14]. Заметим, что такое управление электромагнитными характеристиками материала в спектральной области $\lambda=0.1-0.01 \mathrm{~cm}$ достигается более простым и естественным образом, чем предлагается в работах $[15,16]$.

\section{Конфликт интересов}

Авторы заявляют, что у них нет конфликта интересов.

\section{Список литературы}

[1] Kumar R., Bora D. // J. Appl. Phys. 2010. V. 107. N 5. P. 053303.

[2] Богачев Н.Н., Гусейн-заде Н.Г., Нефедов В.И. // Физика плазмы. 2019. Т. 45. № 4. С. 365-368.

[3] Гусейн-заде Н.Г,, Минаев И.М., Рухадзе А.А., Рухадзе К.3. // Радиотехника и электроника. 2011. Т. 56. № 10. C. $1216-1220$.

[4] Минаев И.М., Сергейчев К.Ф. // Тр. ИОФАН. 2014. Т. 70. C. $186-213$.

[5] Ким А.В., Марков Г.А., Смирнов А.И., Умнов А.Л. // Письма в ЖТФ. 1989. Т. 15. В. 5. С. 34-37.

[6] Пахотин В.А. // Письма в ЖТФ. 2007. Т. 33. В. 8. С. 22-29.

[7] Истомин Е.Н., Карфидов Д.М., Минаев И.М., Рухадзе А.А., Тараканов В.П., Сергейчев К.Ф., Трефилов А.Ю. // Физика плазмы. 2006. Т. 32. № 5. С. 423-435.

[8] Bogachev N.N., Bogdankevich I.L., Gusein-zade N.G., Rukhadze A.A. // Plasma Phys. Rep. 2015. V. 41. N 10. P. 792-798.

[9] Алексеев Е.Е., Казанцев С.Ю., Кононов И.Г., Рогалин В.Е., Фирсов К.Н. // Оптика и спектроскопия. 2018. T. 124. В. 6. С. $790-794$.

[10] Кузенов В.В., Лебо А.И., Лебо И.Г., Рыжкков С.В. Физикоматематические модели и методы расчета воздействия мощных лазерных и плазменных импульсов на конденсированные и газовые среды. М.: Изд-во МГТУ им. Н.Э. Баумана, 2017. $328 \mathrm{c}$.

[11] Гарнов С.В., Щербаков И.А. // УФН. 2011. Т. 181. № 1. C. $97-102$.

[12] Кузьмин Г.П., Минаев И.М., Рухадзе К.З., Тараканов В.П., Тихоневич О.В. // Радиотехника и электроника. 2012. Т. 57. № 5. C. 590-596.

[13] Каплунов И.А., Колесников А.И., Кропотов Г.И., Рогалин В.E. // Оптика и спектроскопия. 2019. Т. 126. В. 3. C. 271-274. 
[14] Лерер А.М., Макеева Г.С. // Письма в ЖТФ. 2018. Т. 44. B. 18. C. 103-110.

[15] Мунина И.В., Тургалиев В.М., Вендик И.Б. // Письма в ЖТФ. 2012. Т. 38. В. 12. C. 59-65.

[16] Вендик И.Б., Вендик О.Г. // ЖТФ. 2013. Т. 83. В. 1. С. 3-28. 